\title{
Correction to: Occurrence of Levonorgestrel in Water Systems and Its Effects on Aquatic Organisms: A Review
}

\author{
Ana Lourdes Oropesa and Laura Guimarães
}

\author{
Correction to: \\ Chapter "Occurrence of Levonorgestrel in Water Systems and Its Effects \\ on Aquatic Organisms: A Review" in: Ana Lourdes Oropesa \\ and Laura Guimarães, Reviews of Environmental Contamination \\ and Toxicology, https://doi.org/10.1007/398_2020_44
}

The author has requested to include the below Acknowledgement section at the end of the chapter.

Acknowledgements This work was supported by UIDB/04423/2020 and UIDP/ 04423/2020, through FCT (Portuguese Foundation for the Science and Technology), and by the REWATER project (FCT/UEFISCDI/FORMAS, WaterJPI/0008/2016) financed under the ERA-NET Cofund WaterWorks2015 (Water JPI)."

The original article was corrected.

The updated online version of this chapter can be found at https://doi.org/10.1007/398_2020_44

\footnotetext{
A. L. Oropesa ( $\square)$

Toxicology Area, University of Extremadura, Caceres, Spain

BRILiC - Biotechnology Research Institute in Livestock and Cynegetic, University of Extremadura, Caceres, Spain

e-mail: aoropesa@unex.es

P. de Voogt (ed.), Reviews of Environmental Contamination and Toxicology Volume 254,

Reviews of Environmental Contamination and Toxicology 254,

https://doi.org/10.1007/398_2020_52
} 